\title{
Motor Speed Maximum Control in the Resonance Ratio Controller for Two-Mass System using Self-Organizing Fuzzy Controller
}

\author{
Ghazanfar Shahgholian $^{1 *}$, Arash Hakimi², Neda Behzadfar ${ }^{1}$ \\ ${ }^{I}$ Department of Electrical Engineering, Najafabad Branch, Islamic Azad University, Najafabad, Iran \\ ${ }^{2}$ Smart Microgrid Research Center, Najafabad Branch, Islamic Azad University, Najafabad, Iran
}

*Corresponding Author: Ghazanfar Shahgholian, Department of Electrical Engineering, Najafabad Branch, Islamic Azad University, Najafabad, Iran

\begin{abstract}
According the importance of controlling the max $\neg i \neg m \neg \neg$ um speed and overshoot in electric motors, and also according to the fact that at the start of a two-mass system with a resonance ratio controller, we will see severe fluctuations in the speed. The control the motor maximum speed in speed desired value is aim in this paper. To take action to achieve this goal, we will use the design incorporating a self-organizing fuzzy control system with a coefficient of resonant two-mass system. Self-organizing fuzzy controller is a combination of fuzzy control and adaptive, which along with the combination of self-organizing fuzzy control meth $\neg 0 \neg d s$, can created instructional with the ability to modify the rules in the knowledge base and incorporated into it, twomass system with a resonance ratio control system, the maximum eng $\neg$ ine speed can be adjusted to any desired value.
\end{abstract}

Keywords: two-mass system; self-organizing fuzzy control; resonance ratio control.

\section{INTRODUCTION}

With industry development and control technique advanced, high performance and high efficiency realize in dynamic control scale [1,2]. A mechanical system can model to one multi-mass system in industry motor drive [3,4]. In many states, two-mass system purpose for first resonance mode [5,6]. In general movement control applications, system consist of a motor, a gear wheel, transfer implements and also a load $[7,8]$. One of the problems in two-mass systems control is convenient and automatic control of the maximum motor speed. The two-mass resonance system is shown in Fig. 1 [9,10]. On the other hand, some important factors in controlling motor optimal, control the amount of overshoot, reduce the ripple amplitude, motor oscillations and reaching a steady state in the shortest time possible [11].

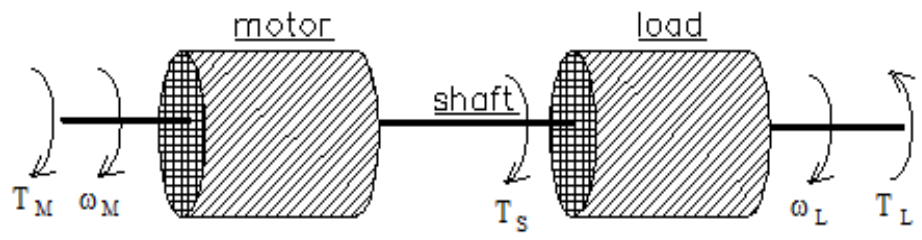

Fig1. Two-mass resonance system

Many papers have been published in the field of two-mass system [12,13]. An application of a fuzzy controller strengthened with a gray estimator to a nonlinear two-mass system control is presented in [14], which fuzzy controller is designed to regulate the speed of the system. A nonlinear approach for variablespeed wind turbine control using a two-mass model and a wind speed estimator is presented in [15], which the model of the two-mass system is motivated by the need to deal with flexible modes induced by the low-speed shaft stiffness. In order to have sufficient damping, in [16] three different controller base on integral-proportional-derivative controller are designed for the speed control of a two-mass system using a normalized model and polynomial method. A quasi-time-optimal, nonlinear statefeedback control for the torsional torque of a two-mass system is proposed in [17], which controller design is based on results of the general framework of optimal control and leverages the assumption of a bang-bang structure for the actuation. The stability analysis of small-signal models of two-mass and 
three-mass wind turbine interconnected to thermal power system is presented in [18], which the use of multi-mass model is motivated by the need to deal with flexible modes induced due to intermittent varying of wind speed and low speed shaft stiffness. A two degree of freedom mass-spring-damper model on a moving lubricated belt is considered in [19], which the friction model includes the boundary, mixed and hydrodynamic regimes of lubrication contact regimes.

In this paper, the design of such a control system will expand under the control of the maximum speed of the motor as one of the two objects two-mass system, and that this functionality to the system, that the user only has to provide the maximum speed of the system in terms of percent of optimum speed to the system, to achieve its goal of controlling the electric motor.

\section{TwO-MASS SySTEM MODEL}

Fig. 2 shows two-mass resonance system block diagram. As was seen in the figure, shaft coupling (TS) consist of sum of two signals which one of them is proportional with difference motor speed $(\omega \mathrm{M})$ and load speed $(\omega \mathrm{L})$ and other one is proportional with difference motor torque angle $(\theta \mathrm{M})$ and load torque angle $(\theta \mathrm{L})$. According to system damping negligibility, shaft torque supposes motor angle difference and load proportional. Choosing three state variables, $\omega \mathrm{L}, \omega \mathrm{M}$ and TS with two input variables, motor torque (TM) and load disturbance torque (TL), system state equations are [20]:

$$
\begin{aligned}
& \frac{d}{d t} \omega_{M}=-\frac{B_{M}}{J_{M}} \omega_{M}-\frac{1}{J_{M}} T_{S}+\frac{1}{J_{M}} T_{M} \\
& \frac{d}{d t} T_{S}=\left(K_{S}-\frac{B_{M} B_{S}}{J_{M}}\right) \omega_{M}-\left(K_{S}-\frac{B_{L} B_{S}}{J_{L}}\right) \omega_{L}-B_{S}\left(\frac{1}{J_{M}}+\frac{1}{J_{L}}\right) T_{S}+\frac{B_{S}}{J_{M}} T_{M}+\frac{B_{S}}{J_{L}} T_{L} \\
& \frac{d}{d t} \omega_{L}=-\frac{B_{L}}{J_{L}} \omega_{L}+\frac{1}{J_{L}} T_{S}-\frac{1}{J_{L}} T_{L} \\
& \frac{d}{d t} \theta_{M}=\omega_{M} \\
& \frac{d}{d t} \theta_{L}=\omega_{L}
\end{aligned}
$$

where $\mathrm{J}_{\mathrm{M}}$ and $\mathrm{J}_{\mathrm{L}}$ are the motor inertia and the load inertia, $\mathrm{B}_{\mathrm{M}}$ and $\mathrm{B}_{\mathrm{L}}$ are the motor viscous damping coefficient and the load viscous damping coefficient, and $\mathrm{K}_{\mathrm{S}}$ is the shaft stiffness. The damping ratio $\eta$ and resonant frequency $\omega_{\mathrm{R}}$ are given by [21]:

$$
\begin{aligned}
& \omega_{R}=\sqrt{\frac{K_{S}}{J_{L}}\left(1+K_{J}\right)} \\
& \eta=\frac{B_{S}}{2} \sqrt{\frac{1}{K_{S} J_{L}}\left(1+K_{J}\right)}
\end{aligned}
$$

where $\mathrm{K}_{\mathrm{J}}=\mathrm{J}_{\mathrm{L}} / \mathrm{J}_{\mathrm{M}}$ is inertia ratio. The anti-resonant frequency is:

$$
\omega_{A}=\sqrt{\frac{K_{S}}{J_{L}}}
$$

If $K_{J}$ and $B_{S}$ are small, mechanical vibration occurs easily. Increasing the inertia ratio $K_{J}=J_{L} / J_{M}$ and shaft stiffness will decrease the mechanical vibration of the system. Apparently, with the increase of $\mathrm{K}_{\mathrm{S}}$ and $\mathrm{J}_{\mathrm{L}}$, damping ratio goes down. Good response characteristics depend on both damping ratio and undamping nature frequency. One important factor has been noticed, in that the resonance characteristics of a two-mass system can be described by its resonance ratio $\left(\mathrm{K}_{\mathrm{R}}\right)$ which is the quotient of the antiresonance frequency and resonance frequency of the system: 
$K_{R}=\frac{\omega_{R}}{\omega_{A}}=\sqrt{1+K_{J}}$

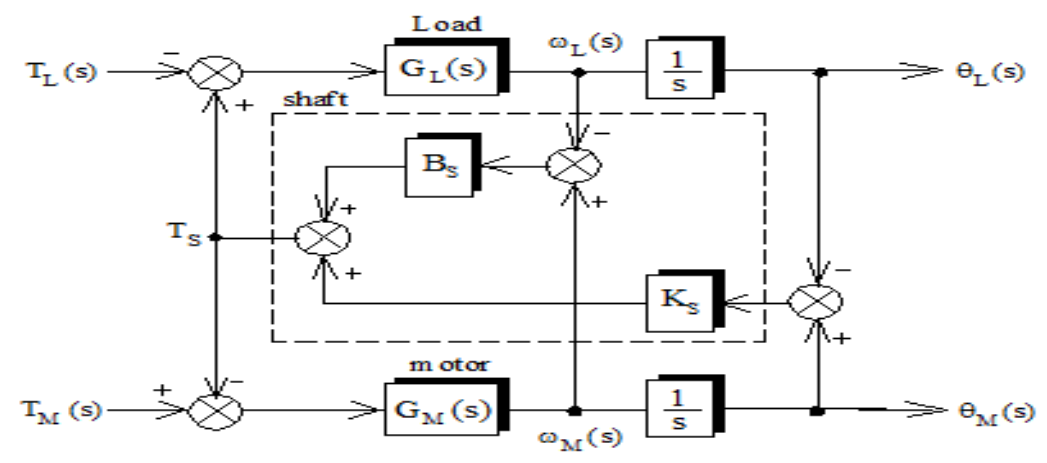

Fig2. Two-mass resonance system

\section{Two-MASS RESONANCE RATIO CONTROL}

Resonance ratio control is one of the effective control methods for two-mass resonance system determined where ratio between motor resonance frequency and robotic arm base on measured reaction feedback [22,23]. In two-mass resonance systems couple and motor speed are measurable only and rest of variables must estimate by observers [24,25]. Fig. 3 show the block diagram of the two-mass resonce system controller. It consists two-mass system, disturbance observer and resonance ratio controller. Fig. 4 show the block diagram of transfer function controller of two-mass resonce controller. In the resonant ratio controller, disturbance observer is much faster than the resonance frequency and anti-resonance, so used the factor $1-\mathrm{K}$ in feedback estimated disorder.

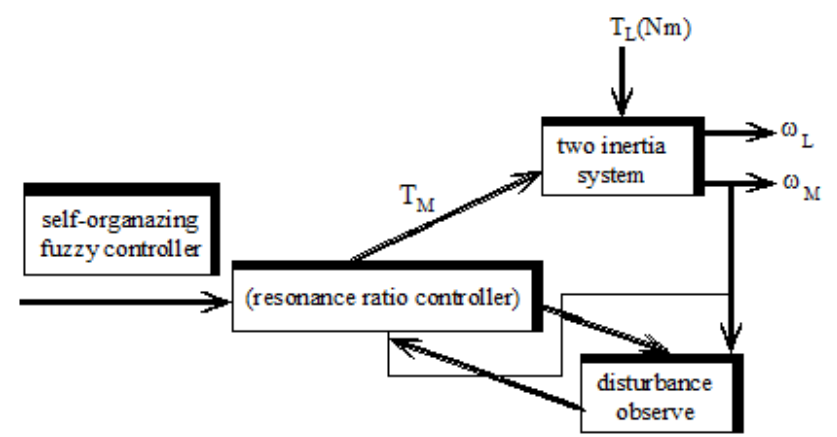

Fig3. Block digram of two-mass resonance system controller

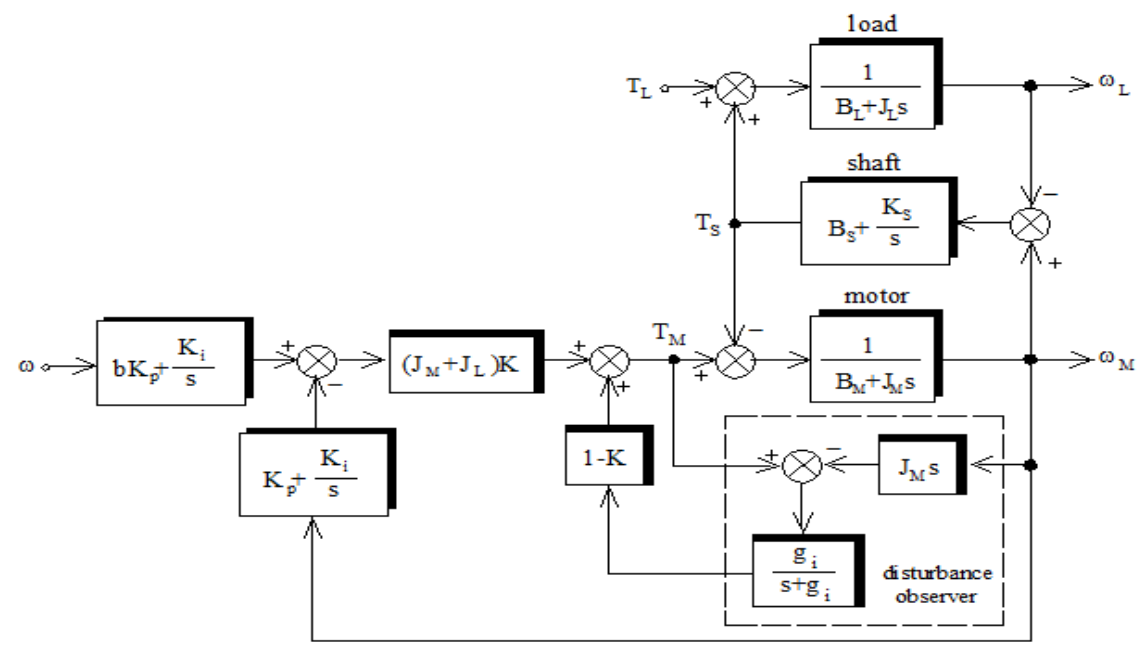

Fig4. Transfer function controller of two-mass resonce system

\section{Self-Organizing Fuzzy CONTROller}

The overall performance of the self-organizing fuzzy controller based on the Fig. 5, so that in the first phase of the phase of the corresponding entry [26,27]. And then modify the existing rules in the 
Motor Speed Maximum Control in the Resonance Ratio Controller for Two-Mass System using SelfOrganizing Fuzzy Controller

knowledge base will help adaptive control method and base on the law selected has been modified, the calculated desired output and after passing through a unit De-fuzzification, is non-fuzzy and is applied to the system. First, with the help of table I, which is experimentally obtained, 49 of the initial values to use self-organizing fuzzy control system is available in the knowledge base, accordingly, when entering the desired speed and speed measurement error into the system, so of fuzzy logic inference based on respective one of 49 of the existing knowledge base, is selected. Non-fuzzy coefficient of resonant controller and then to apply two-mass system $[28,29]$.

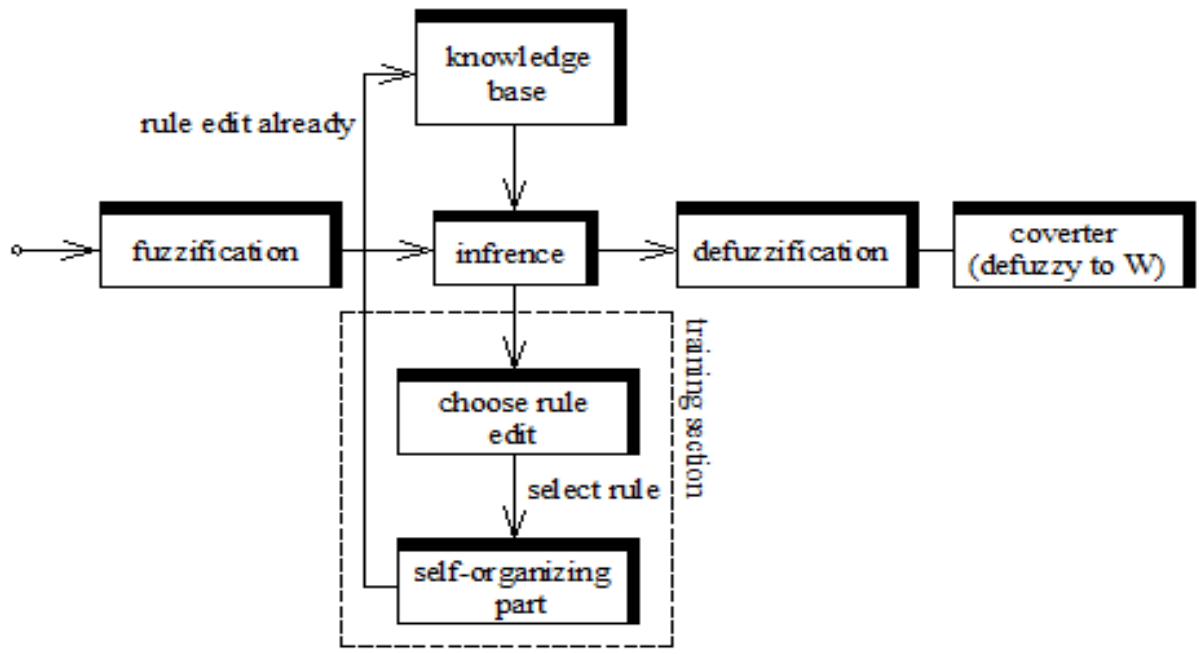

Fig1. The part of the self-organizing fuzzy controller

Then, with the help of self-organizing adaptive control methods, fuzzy decision table values are modified. Self-organizing part, as follows to change the rules in the knowledge base acts:

$$
\begin{aligned}
& E=\frac{1}{2}\left[y(t)-y_{s p}\right]^{2} \\
& \overline{c_{l}}(k+1)=\overline{c_{l}}(k)-\alpha \frac{\partial E}{\partial \overline{c_{1}}}
\end{aligned}
$$

where $C_{L}(k)$ is the membership function of law $L$ in the course of training $k, C_{L}(k+1)$ is the membership function of law $\mathrm{L}$ in the course of training, $\alpha$ is learning rate and $\partial \mathrm{E} / \partial \mathrm{c}_{1}$ is derivative function when compared with $\mathrm{C}_{1}$.

$\frac{\partial E}{\partial \overline{c_{1}}}=\frac{\mu_{l}(e) \times \mu_{l}(c e) \times\left(y(t)-y_{s p}\right)}{\sum_{l=1}^{n}\left(\mu_{l}(e) \times \mu_{l}(c e)\right)}$

where $\mu_{1}(\mathrm{e})$ is join the error of the law $\mathrm{L}, \mu_{1}(\mathrm{ce})$ is join the error changes the law $\mathrm{L}, \mathrm{Y}_{\mathrm{sp}}$ is value period is required and $\mathrm{y}(\mathrm{t})$ is the value of the measured period.

Table1. KNOWLEDGE BASE AND RULES AVAILABLE AT THE TIME NT IN TRAINING K

\begin{tabular}{|l|l|l|l|l|l|l|l|l|}
\hline & de & NB & NM & NS & ZE & PS & PM & PB \\
\hline e & center & -0.6 & -0.4 & -0.2 & 0 & 0.2 & 0.4 & 0.6 \\
\hline NB & -0.6 & -0.6 & -0.6 & -0.6 & -0.6 & -0.4 & -0.2 & 0 \\
\hline NM & -0.4 & -0.6 & -0.6 & -0.6 & -0.4 & -0.2 & 0 & 0.2 \\
\hline NS & -0.2 & -0.6 & -0.6 & -0.4 & -0.2 & 0 & 0.2 & 0.4 \\
\hline ZE & 0 & -0.6 & -0.4 & -0.2 & 0 & 0.2 & 0.4 & 0.6 \\
\hline PS & 0.2 & -0.4 & -0.2 & 0 & 0.2 & 0.4 & 0.6 & 0.6 \\
\hline PM & 0.4 & -0.2 & 0 & 0.2 & 0.4 & 0.6 & 0.6 & 0.6 \\
\hline PB & 0.6 & 0 & 0.2 & 0.4 & 0.6 & 0.6 & 0.6 & 0.6 \\
\hline
\end{tabular}


Motor Speed Maximum Control in the Resonance Ratio Controller for Two-Mass System using SelfOrganizing Fuzzy Controller

\section{Simulation Results}

In this section the simulation results of the system is shown. Items listed in the table II, is considered as a common factor in all the simulations. In this part the initial conditions include the follows: $\mathrm{J}_{\mathrm{M}}=0.3$, $\mathrm{J}_{\mathrm{L}}=1.5, \mathrm{~T}_{\mathrm{L}}=0.1, \mathrm{~K}=6$. Curves for maximum desired value by $4 \%, 7 \%$ and $9 \%$ to curve the system in the non-use of self-organizing fuzzy controller are show in Fig. 6. Fig. 7 to better illustrate the distinction between curves under $4 \%, 7 \%, 9 \%$ is shown. As seen, in the case of a self-organizing system is no fuzzy controller, fluctuations in engine speed is observed. We also see the maximum speed with 1073 the amount of non-use of the controller. But after using fuzzy self-organizing systems by setting the maximum speed on the optimal value, the excess amount of base speed can be expressed in terms of percentage $(4 \%=1040$ and $1090=1070=7 \%$ and $9 \%)$, does not exceed the maximum speed in the cycle of the set and also the volatility has decreased to a considerable extent and the cycle is under control. Even when set to the maximum rate of $9 \%$, we will see that. Although in the case of self-organizing fuzzy controller, we have a maximum speed, but the advantage of this controller to reduce engine speed fluctuations, will show itself well. Figs. 8 and 9 was shown the effect of the load torque to the goal control system and we can see that reached to maintain maximum speed at the desired level and also decreased levels of volatility through the use of the controller. Due to closer look at system performance in terms of torque load in different conditions control system fuzzy self-organizing, in Figs. 10 and 11, have shown that the torque load with a value of $50 \mathrm{~N}$.m since the $25 \mathrm{~s}$, the system as it is expected to continue its activities and the addition of load torque will have little impact on the maintenance of the maximum speed at the desired level and the volatility also does not have much impact and to the use of this system greatly reduced the volatility.

TABLE2. COMMON FACTORS IN SIMULATION

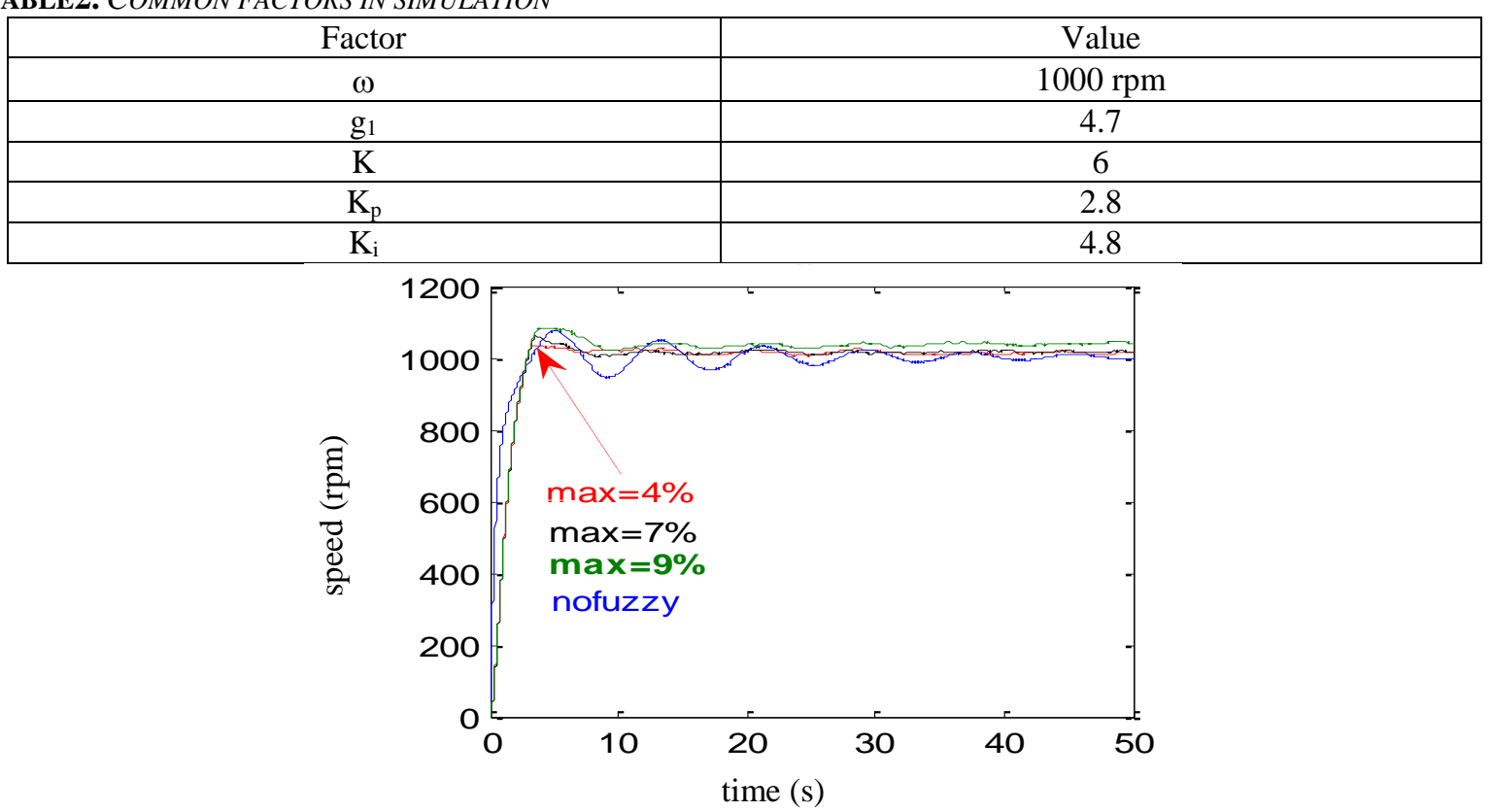

Fig2. Curves for maximum desired value by 4\%, 7\%, 9\% to curve the system in the non-use of self-organizing fuzzy controller

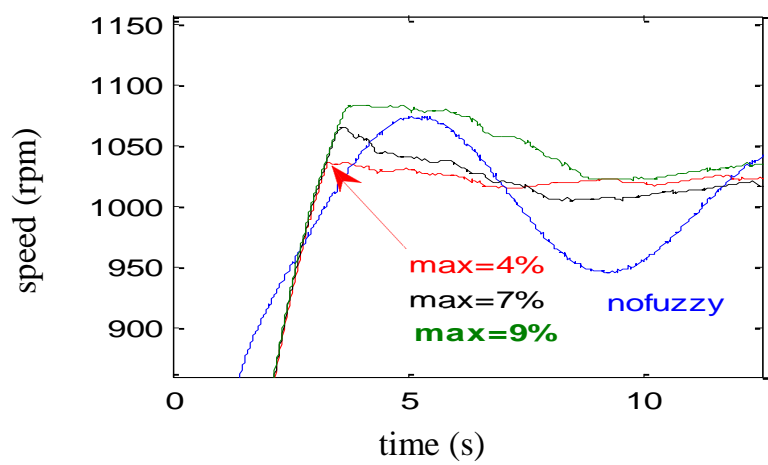

Fig3. Zoom of the figure 6 
Motor Speed Maximum Control in the Resonance Ratio Controller for Two-Mass System using SelfOrganizing Fuzzy Controller

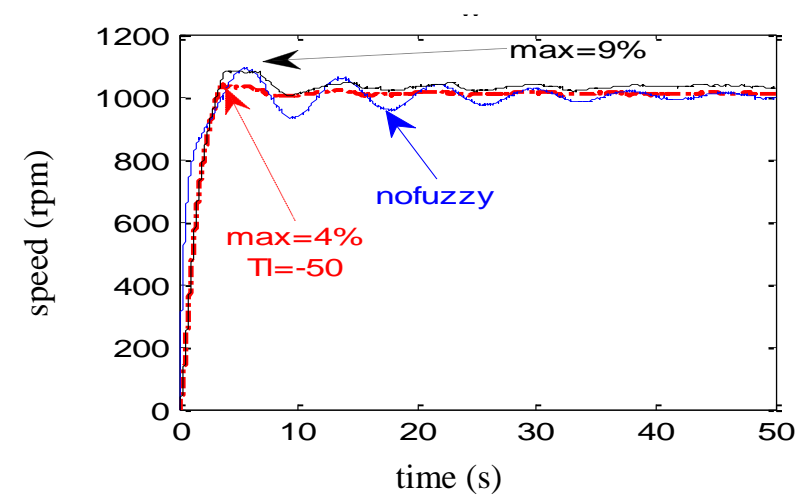

Fig4. The curve compared to the maximum amount of 5\% and 7\% toward curve the system in the non-use of selforganizing fuzzy controller with torque load $50 \mathrm{Nm}$

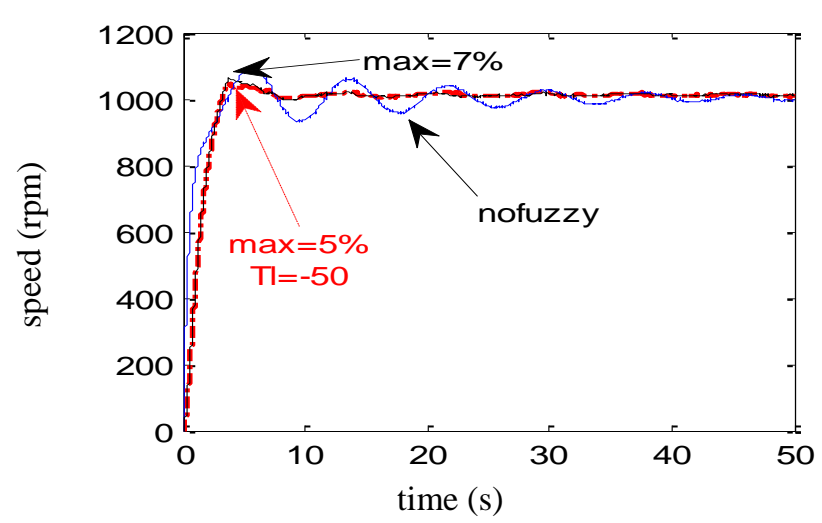

Fig5. The curve compared to the maximum amount of 5\% and 7\% toward curve the system in the non-use of selforganizing fuzzy controller with torque load $50 \mathrm{Nm}$

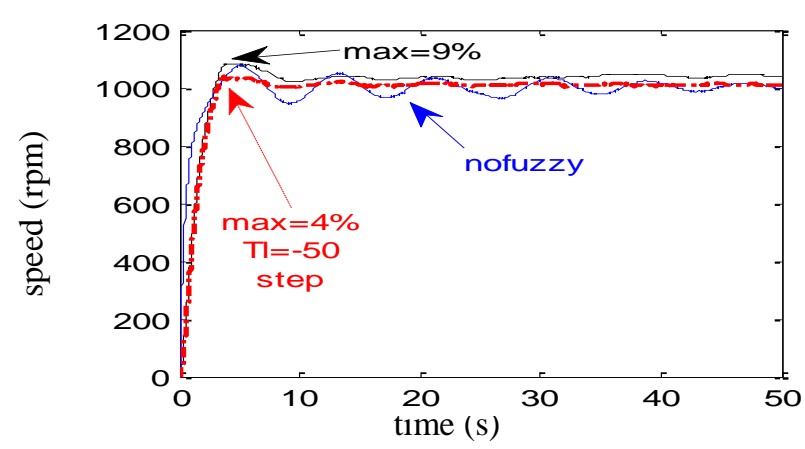

Fig6. The curve compared to the maximum amount of 4\% and 9\% toward curve the system in the non-use of selforganizing fuzzy controller with torque load $50 \mathrm{Nm}$ with a step function at the time of 25 seconds

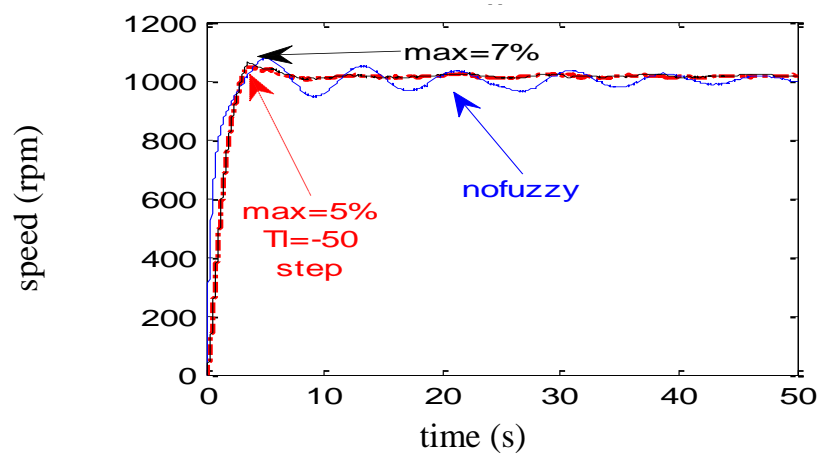

Fig7. The curve compared to the maximum amount of 5\% and 7\% toward curve the system in the non-use of self-organizing fuzzy controller with torque load $50 \mathrm{Nm}$ with a step function at the time of 25 seconds

International Journal of Research Studies in Electrical and Electronics Engineering (IJRSEEE) Page | 6 


\section{CONCLuSion}

As has been shown in experimental results simulated, with fuzzy self-organizing systems can be controlled the maximum value motor speed in the controller coefficient of resonant two-mass system. By providing desired maximum value as input system, observed that in the whole process of the maximum motor speed does not exceed the amount set and also minimizes the oscillations in the system and reduced the extent of it. Because of this feature, in order to control the motor speed of the system, it can be used in various processes that maximize the speed and motor oscillations and stable operation of the system is important.

\section{REFERENCES}

[1] K. Khani, G. Shahgholian, "Analysis and optimization of frequency control in isolated microgrid with doublefed induction-generators based wind turbine", Journal of International Council on Electrical Engineering, Vol. 9, No. 1, pp. 24-37, Feb. 2019.

[2] G. Shahgholian, K. Khani, M. Moazzami, "Frequency control in autanamous microgrid in the presence of DFIG based wind turbine", Journal of Intelligent Procedures in Electrical Technology, Vol. 6, No. 23, pp. 312, Autumn 2015.

[3] E.J. Fuentes, C.A. Silva, J.I. Yuz, "Predictive speed control of a two-mass system driven by a permanent magnet synchronous motor", IEEE Trans. on Industrial Electronics, Vol. 59, No. 7, pp. 2840-2848, 2012.

[4] T. Orlowska-Kowalska, M. Dybkowski, K. Szabat, "Adaptive sliding-mode neuro-fuzzy control of the twomass induction motor drive without mechanical sensors", IEEE Trans. on Industrial Electronics, Vol. 57, pp. 553-564, Feb. 2010.

[5] G. Shahgholian, P. Shafaghi, Z. Azimi, "State space model and speed control of two-mass resonant system using state feedback design", International Journal on Technical and Physical Problems of Engineering, Vol. 6, No. 2, pp. 111-116, Sep. 2014.

[6] B. Dyniewicz, D. Pisarski, C.I. Bajer, "Vibrations of a mindlin plate subjected to a pair of inertial loads moving in opposite directions", Journal of Sound and Vibration, Vol. 386, pp. 265-282, Jan. 2017.

[7] G. Shahgholian, N. Izadpanahi, "Improving the performance of wind turbine equipped with DFIG using STATCOM based on input-output feedback linearization controller", Energy Equipment and Systems, Vol. 4, No. 1, pp. 65-79, June 2016.

[8] G. Shahgholian, "Controller design for three-mass resonant system based on polynomial method", International Journal of Science, Technology and Society, Vol. 5, No. 2, pp. 13-25, March 2017.

[9] A. Jafari, G. Shahgholian, M. Zamanifar, "Stability analysis of doubly-fed induction generator wind turbine systems using modal analysis", Iranian Journal of Electrical and Computer Engineering, Vol. 17, No. 3, pp. 173-189, Autumn 2019.

[10]G. Shahgholian, "Modeling and simulation of a two-mass resonant system with speed controller", International Journal of Infoarmation and Electronics Engenieering, Vol. 3, No. 4, pp. 365-369, July $2013 .$.

[11] G. Shahgholian, J. Faiz, "An analytical approach to synthesis and modeling of torque control strategy for twomass resonant systems", International Review of Automatic Control, Vol. 2, No. 4, pp. 459-468, July 2009.

[12]Z. Lin, J. Liu, Y. Niu, "Dynamic response regulation of non-linear feedback linearised wind turbine using a two-mass model", IET Control Theory and Applications, Vol. 11, No. 6, pp. 816-826m March 2017.

[13]F.B. Mathis, R. Mukherjee, "Apex height control of a two-mass robot hopping on a rigid foundation", Mechanism and Machine Theory, Vol. 105, pp. 44-57, Nov. 2016.

[14] K. Erenturk, "Gray-fuzzy control of a nonlinear two-mass system", Journal of the Franklin Institute, Vol. 347, No. 7, pp. 1171-1185, Sep. 2010.

[15]B. Boukhezzar, H. Siguerdidjane, "Nonlinear control of a variable-speed wind turbine using a two-mass model", IEEE Trans. on Energy Conversion, Vol. 26, No. 1, pp. 149-162, March 2011.

[16]C. Ma, J. Cao, Y. Qiao, "Polynomial-method-based design of low-order controllers for two-mass systems", IEEE Trans. on Ind. Ele., Vol. 60, No. 3, pp. 969-971, March 2013.

[17]E. Fuentes, D. Kalise, R.M. Kennel, "Smoothened quasi-time-optimal control for the torsional torque in a two-mass system", IEEE Trans. on Industrial Electronics, Vol. 63, No. 6, pp. 3954-3963, June 2016.

[18] V. P. Singh, N. Kishor, P. Samuel, N. Singh, "Small-signal stability analysis for two-mass and threemass shaft model of wind turbine integrated to thermal power system", Computers and Electrical Engineering, Vol. 78, pp. 271-287, Sep. 2019.

[19] A. Niknam, K. Farhang, "Friction-induced vibration in a two-mass damped system", Journal of Sound and Vibration, Vol. 456, pp. 454-475, Sep. 2019.

International Journal of Research Studies in Electrical and Electronics Engineering (IJRSEEE) Page 7 
Motor Speed Maximum Control in the Resonance Ratio Controller for Two-Mass System using SelfOrganizing Fuzzy Controller

[20] G. Shahgholian, P. Shafaghi, M. Zinali, S. Moalem, "State space analysis and control design of two-mass resonant system", Proceeding of the IEEE/ICCEE, pp.668-672, Dubai, EUA, Dec. 2009.

[21] G. Shahgholian, J. Faiz, P. Shafaghi, "Analysis and simulation of speed control for two-mass resonant system", Proceeding of the IEEE/ICCEE, pp. 668-672, Dubai, EUA, Dec. 2009.

[22] S.Katsura, K.Ohnishi, "Force servoing by flexible manipulator based on resonance ratio control", IEEE Trans. on Indudustrial Electronics, Vol. 54, No. 1, pp. 539-547, Feb. 2007.

[23] S. Yorozu, S. Katsura, "Vibration suppression control of 2- mass resonant system for haptic tele-operation", Proceeding of the IEEE/AMC, pp. 655-660, Mar. 2010.

[24] S. Komada, K. Iyama, K.Yubai, T. Hori, "Suppression of limit cycle and improvement of robust performance in two-mass resnant systems with nonlinearity", Proceeding of the IEEE/IECON, Vol. 3, pp. 1704-1709, Nov./Dec. 2001.

[25] T. Orlowska-Kowalska, M. Kaminski, "FPGA implementation of the multilayer neural network for the speed estimation of the two-mass drive system", IEEE Trans. on Industrial Informatics, Vol. 7, No. 3, pp. 436-, Aug. 2011.

[26] E. Hosseini, E. Aghadavoodi, G. Shahgholian, H. Mahdavi-Nasab, "Intelligent pitch angle control based on gain-scheduled recurrent ANFIS", Journal of Renewable Energy and Environment, Vol. 6, No. 1, pp. 36-45, 2019.

[27][18-1] E. Aghadavoodi, G. Shahgholian, "A new practical feed-forward cascade analyze for close loop identification of combustion control loop system through RANFIS and NARX", Applied Thermal Engineering, Vol. 133, pp. 381-395, March 2018.

[28]E.H. Mamdani, "Application of fuzzy algorithms for control of simple dynamic plant", Proceeding of the IEEE/PIEE, Vol. 121, No. 12, pp. 1585-1588, Dec. 1974.

[29] J. Lin, R.J. Lian, "Self-organizing fuzzy controller for gas-assisted injection molding combination systems", IEEE Trans. on Control Systems Technology, Vol. 18, No. 6, pp. 1413-1421, Nov. 2010.

Citation: Ghazanfar Shahgholian, et.al., (2020). “Motor Speed Maximum Control in the Resonance Ratio Controller for Two-Mass System using Self-Organizing Fuzzy Controller”. International Journal of Research Studies in Electrical and Electronics Engineering (IJRSEEE), 6(1), pp 1-8. DOI: http://dx.doi. org/10.20431/2454-9436.0601001

Copyright: (C) 2020 Authors. This is an open-access article distributed under the terms of the Creative Commons Attribution License, which permits unrestricted use, distribution, and reproduction in any medium, provided the original author and source are credited. 